Historic, Archive Document

Do not assume content reflects current scientific knowledge, policies, or practices. 


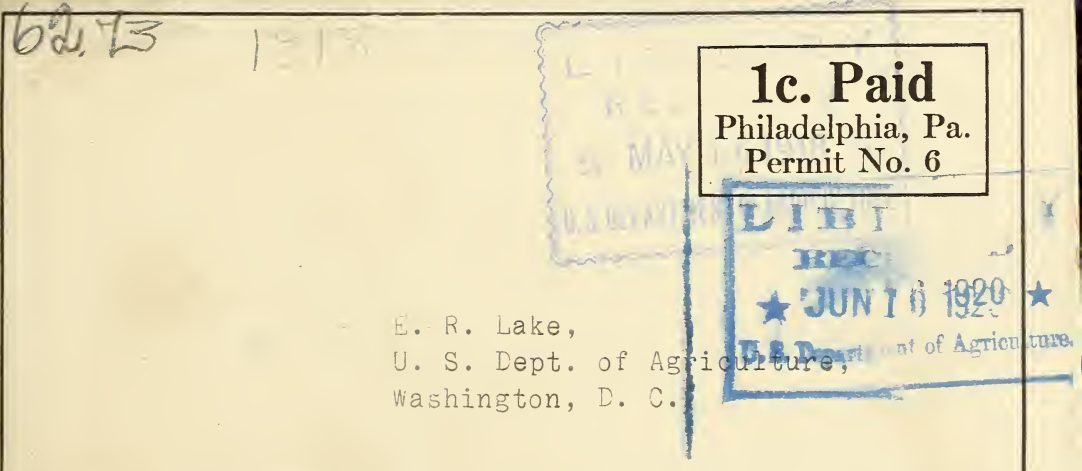

This invitation is intended for those who are not now our patrons, but is mailed also to some of our regular customers who may have already received Burpee's Annual for 1918, with a request to "pass it along" to a neighbor or friend who would be interested in Burpee-Quality Seeds. 


\section{Burpee's Annual for 1918}

We are sending this "Combination Post Card" to make it easy for you

to get Burpee's Annual for 1918. All you need do is write your name and address plainly, affix a one-cent stamp, mail the post card, and the Burpee Annual for 1918 will come to you by return mail. Please remember that your order will be filled (should you decide to order after reading the Catalog) with equal promptness. Promptness and accuracy are a part of the Burpee service, and we

have unsurpassed facilities for proper

execution of all seed orders in the new

\section{Burpee Buildings}

Philadelphia

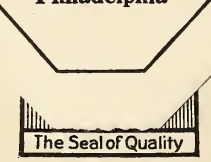

